\title{
Antiangiogenic treatment for multiple CNS hemangioblastomas
}

\author{
Riklin, C ; Seystahl, K ; Hofer, S ; Happold, C ; Winterhalder, R ; Weller, M
}

\begin{abstract}
Background: Hemangioblastomas represent rare benign tumors of the central nervous system. In the case of metastatic spread and limited surgical options, systemic treatment may be considered. However there is no standard of care beyond surgery. Case Report: We report the cases of 2 patients with progressive multilocular hemangioblastomas, who showed clinical benefit and radiological stabilization of tumor growth after treatment with bevacizumab, an antibody against the vascular endothelial growth factor. Conclusion: Our case reports suggest activity of bevacizumab in hemangioblastomas after failure of standard therapeutic options.
\end{abstract}

DOI: https://doi.org/10.1159/000341075

Posted at the Zurich Open Repository and Archive, University of Zurich ZORA URL: https://doi.org/10.5167/uzh-64667

Journal Article

Accepted Version

Originally published at:

Riklin, C; Seystahl, K; Hofer, S; Happold, C; Winterhalder, R; Weller, M (2012). Antiangiogenic treatment for multiple CNS hemangioblastomas. Onkologie, 35(7-8):443-445.

DOI: https://doi.org/10.1159/000341075 


\section{Antiangiogenic treatment for multiple CNS hemangioblastomas}

Anti-angiogene Therapie bei multiplen Hämangioblastomen im ZNS

Short title: Bevacizumab for multiple hemangioblastomas

Kurztitel: Bevacizumab bei multiplen Hämangioblastomen 


\section{Antiangiogenic treatment for multiple CNS hemangioblastomas}

\section{Anti-angiogene Therapie bei multiplen Hämangioblastomen im ZNS}

Christian Riklin ${ }^{1^{*}}$, Katharina Seystahl ${ }^{2}$, Silvia Hofer ${ }^{3}$, Caroline Happold ${ }^{2}$, Ralph Winterhalder ${ }^{1}$, Michael Weller ${ }^{2}$

${ }^{1}$ Divison of Medical Oncology, Cantonal Hospital of Lucerne, Lucerne, Switzerland, ${ }^{2}$ Department of Neurology, University Hospital Zurich, Zurich Switzerland, ${ }^{3}$ Department of Medical Oncology, University Hospital Zurich, Zurich, Switzerland Correspondence to: Christian Riklin, MD, Division of Medical Oncology, Cantonal Hospital of Lucerne, CH - 6000 Lucerne 16, Switzerland, phone +414120558 73, fax +414120558 62, christian.riklin@ksl.ch

Keywords: hemangioblastoma, bevacizumab, von Hippel-Lindau syndrome, antiangiogenesis

Schlüsselwörter: Hämangioblastom, Bevacizumab, von Hippel-Lindau-Syndrom, Antiangiogenese 


\section{Summary}

Background: Hemangioblastomas represent rare benign tumors of the central nervous system. In case of multilocular spread disease and limited surgical options, systemic treatment may be considered. However, there is no standard of care beyond surgery.

Case report: We report 2 patients with progressive multilocular hemangioblastomas who showed clinical benefit and radiological stabilization of tumor growth after treatment with bevacizumab, an antibody against vascular endothelial growth factor (Avastin $\AA$, Roche).

Conclusion: Our case reports suggest activity of bevacizumab in hemangioblastomas after failure of standard therapeutic options.

\section{Zusammenfassung}

Hintergrund: Hämangioblastome sind seltene Tumore des zentralen Nervensystems. Im Fall einer metastatischen Aussaat und bei begrenzten chirurgischen Möglichkeiten kann eine Systemtherapie in Betracht gezogen werden. Abgesehen von der Resektion gibt es jedoch aktuell keine Standardtherapie.

Kasuistik: Wir berichten von zwei Patienten mit progredienten multiplen Hämangioblastomen, die unter einer Behandlung mit Bevacizumab, einem Antikörper gegen den vaskulären endothelialen Wachstumsfaktor (Avastin $\AA$, Roche) klinisch profitierten und bildgebend eine Stabilisierung der Erkrankung zeigten.

Schlussfolgerung: Unsere Fallberichte zeigen eine mögliche Wirksamkeit von Bevacizumab bei Hämangioblastomen, wenn die Optionen der Standardtherapie ausgeschöpft sind. 


\section{Introduction}

Hemangioblastomas are rare benign tumors of the central nervous system (CNS) accounting for about $2 \%$ of all intracranial tumors [1]. Surgical resection is the standard of care. However, multiple cerebral hemangioblastomas may require systemic treatment. We report 2 patients with progressive multilocular hemangioblastoma who were treated with the vascular endothelial growth factor (VEGF) antibody bevacizumab (Avastin $\AA^{\circledR}$, Roche). The experimental treatment was administered as a compassionate use of the drug after written informed consent of the patient or, in case 1, of the patient's wife as the responsible representative.

\section{Case 1}

A 53-year-old man was admitted in Lucerne in July 2010 with seizures, somnolence and confusion. The clinical deterioration had developed over the course of three months. Twelve years earlier he had been diagnosed with cerebellar hemangioblastoma which was completely resected. MRI scan revealed multiple lesions in the brain, the brain stem and the spine (fig. 1A) with prominent perifocal edema (fig. 1B). A large frontotemporal biopsy confirmed recurrent hemangioblastoma WHO grade 1. A mutation of the von Hippel-Lindau (VHL) gene was ruled out. The patient received antiepileptic treatment with carbamazepine and intravenous dexamethasone (32 $\mathrm{mg}$ per day) over the course of 14 days without any improvement of his clinical condition. In the absence of evidence-based systemic therapy, we started antiangiogenic treatment with bevacizumab $(10 \mathrm{mg} / \mathrm{kg})$. Eight days after the first infusion the patient's general condition had greatly improved. Treatment was continued at 14 days intervals whereas dexamethasone was tapered and finally stopped. MRI showed stable disease and reduction of the edema (fig. 1C and D). After a rehabilitation program the patient was discharged in October 2010. He has gained autonomy in activities of daily living with a Karnofsky performance score of 80 with occasional seizures. In conclusion, the clinical observation of the rapid decline before the start of bevacizumab and remarkable and prompt improvement of the patient's condition after the start of bevacizumab together with a stable course of the disease hereafter was suggestive of activity of bevacizumab. The durable reduction of edema despite withdrawal of steroids confirmed the activity of bevacizumab. In April 2011, however, bevacizumab was stopped because of 
clinical and radiological progression (fig. 1E). In July 2011 the patient is still alive, but needs help in all activities of daily living.

\section{Case 2}

A 67-year-old man had a solitary left cerebellar capillary hemangioblastoma WHO grade 1 resected in August 1994. Since July 2009 he developed a progressive gait disorder which led to the diagnosis of local tumor recurrence. He underwent repeat gross total resection in December 2009 in Zurich. No lesions suggestive of VHL disease were identified and no germline mutations were found upon analysis of exons 1-3 of the VHL gene. Cerebrospinal fluid protein was elevated and spinal MRI showed multiple contrast-enhancing lesions; cranial MRI showed mild leptomeningeal contrast enhancement (fig. 2A). The patient received no further treatment and the spinal lesions progressed over months (fig. 2B). Proof of multilocular disease along the spinal axis was obtained by biopsy of one spinal lesion in July 2010. The spinal manifestation of the disease was reflected by the clinical pattern of the mainly sensory gait disturbance involving pathological sensory evoked potentials, severe pallhypesthesia and positive Romberg's sign. The gait disorder further progressed, leading to severe disability with inability to walk a few meters without support. Since surgery, radiation and chemotherapy were not considered promising therapeutic options, sunitinib, a multi-targeted receptor tyrosine kinase inhibitor, was started in September 2010, based on the assumption that VEGF receptor signal transduction was required for tumor cell proliferation. After one week of sunitinib treatment $(50 \mathrm{mg} / \mathrm{d})$, the patient developed headaches and episodes of impaired consciousness caused by CSF flow obstruction triggered by hemorrhage observed in the lateral ventricles on CT scan, and confirmed by lumbar puncture. Sunitinib was stopped since an association with the bleeding could not be excluded. A ventriculoperitoneal shunt was placed and the patient recovered slowly over the course of several weeks. Still, the follow-up craniospinal MRI in December 2010 showed further progression of both intraspinal tumor manifestations and contrast enhancement of the cerebral leptomeninges (fig. $2 \mathrm{C}$ ). After the resolution of the bleeding was confirmed by craniospinal MRI and CSF analysis, the patient was started on bevacizumab (10 mg/kg, every 2 weeks). Gait improved slowly and almost no signs of ataxia were left by March 2011, after 4 applications of bevacizumab. The MRI was virtually unchanged at this time (data not shown). Bevacizumab was 
continued and the MRI after 4 months of treatment with bevacizumab (5/2011) showed stable disease again (fig. 2D). To date, the patient walks 4 kilometers every day without any support; his Karnofsky performance status improved from $70 \%$ to $90 \%$.

\section{Discussion}

Benign hemangioblastomas of the central nervous system may occur sporadically, but are mostly seen in association with VHL disease. Patients with VHL disease usually have less severe neurological symptoms and present at an earlier age than patients with sporadic lesions [2, 3]. Microsurgical resection is the treatment of choice. For unresectable symptomatic tumors, stereotactic radiosurgery may be an alternative approach with less durable local control [4]. Despite complete excision, de novo tumors can develop years after the initial diagnosis [5]. Hemangioblastomas develop from neoplastic stromal cells producing VEGF [6-8]. By consequence, hemangioblastomas present histologically with a dense vascular network. Therefore, antiangiogenic treatment seems logical when complete microsurgical resection is impossible. Sunitinib is one of the most frequently used antiangiogenic agent and currently under investigation in a phase II study (ClinicalTrials.gov Identifier: NCT00589784). So far, no experience with intravenous bevacizumab has been published; however, intravitreal bevacizumab has been described in patients with VHL-associated retinal hemangioblastomas $[9,10]$. To date one open phase 0 study investigates bevacizumab in hemangioblastomas (ClinicalTrials.gov Identifier: NCT01015300). The two patients described here experienced an impressive and long-lasting clinical benefit. They demonstrated radiological stabilisation of symptomatic multifocal hemangioblastomas in the brain and spine with bevacizumab. The failure to induce objective remission suggests that VEGF is not a survival factor for the tumor cells whereas the induction of stable disease indicates that VEGF may be a growth factor in this disease. The clinical benefit is difficult to explain, but may be caused by a reduction of perfusion and edema and possibly improved perfusion of adjacent brain parenchyma. Possible mechanisms are the known decreases in capillary density, microvascular flow and blood vessel permeability in response to bevacizumab [11, 12]. We conclude that bevacizumab merits further investigation in this condition. 


\section{Authors' disclosures of potential conflicts of interest}

MW has received research support and honoraria for advisory board participation and lecturing from Roche (Basel, Switzerland), the manufacturer of bevacizumab (Avastin $\AA$ ). The other authors declare no potential conflicts of interest.

\section{Figure legends}

\section{Figure 1}

Cranial MRI of patient 1, showing contrast-enhancing lesions (A, 7/2010) and cerebral edema (B, 7/2010), with stable disease after a period of 6 months ( $C$, 1/2011) and reduction of cerebral edema (D, 1/2011). Progression occurred after 9 months of treatment ( $E, 4 / 2011)$ (Department of Diagnostic Radiology and Nuclear Medicine, Cantonal Hospital of Lucerne, Lucerne, Switzerland).

\section{Figure 2}

Spinal and cranial MRI of patient 2, showing mild leptomeningeal contrast-enhancing lesions (A, 12/2009) which progressed over a time period of 9 months (B, 8/2010). Further progression occured after 4 additional months including one week treatment with sunitinib $(C, 12 / 2010)$. In contrast, contrast-enhancing lesions have been unchanged after 4 months of treatment with bevacizumab (D,5/2011) (MRI scans: courtesy of Radiology Institute Lindberg, Winterthur, Switzerland).

\section{Consent}

Written informed consent was obtained from the patients for publication of this report and any accompanying images. A copy of the written consent is available for review by the Editor-in-Chief of this journal.

\section{Authors' contributions}


CR was responsible for conception and writing of the article and for patient care; KS was responsible for writing of the article and for patient care. $\mathrm{CH}$ was responsible for patient care. $\mathrm{SH}, \mathrm{RW}$ and MW supervised the article and patient care.

\section{References:}

1 Choyke PL, Glenn GM, Walther MM, Patronas NJ, Linehan WM, Zbar B: Von hippel-lindau disease: Genetic, clinical, and imaging features. Radiology 1995;194:629-642.

2 Takai K, Taniguchi M, Takahashi H, Usui M, Saito N: Comparative analysis of spinal hemangioblastomas in sporadic disease and von hippel-lindau syndrome. Neurol Med Chir (Tokyo) 2010;50:560-567.

3 Richard S, Beigelman C, Gerber S, Van Effenterre R, Gaudric A, Sahel M, Binaghi M, De Kersaint-Gilly A, Houtteville JP, Brunon JP, et al.: [does hemangioblastoma exist outside von hippel-lindau disease?]. Neurochirurgie 1994;40:145-154.

4 Asthagiri AR, Mehta GU, Zach L, Li X, Butman JA, Camphausen KA, Lonser RR: Prospective evaluation of radiosurgery for hemangioblastomas in von hippellindau disease. Neuro-Oncology 2010;12:80-86.

5 Lonser RR, Glenn GM, Walther M, Chew EY, Libutti SK, Linehan WM, Oldfield EH: Von hippel-lindau disease. The Lancet 2003;361:2059-2067.

6 Krieg M, Marti $\mathrm{HH}$, Plate $\mathrm{KH}$ : Coexpression of erythropoietin and vascular endothelial growth factor in nervous system tumors associated with von hippel-lindau tumor suppressor gene loss of function. Blood 1998;92:3388-3393.

7 Wizigmann-Voos S, Breier G, Risau W, Plate KH: Up-regulation of vascular endothelial growth factor and its receptors in von hippel-lindau disease-associated and sporadic hemangioblastomas. Cancer Research 1995;55:1358-1364.

8 Jenny B, Harrison JA, Baetens D, Tille JC, Burkhardt K, Mottaz H, Kiss JZ, Dietrich PY, De Tribolet N, Pizzolato GP, Pepper MS: Expression and localization of vegf-c and vegfr-3 in glioblastomas and haemangioblastomas. The Journal of Pathology 2006;209:34-43. 
9 de Klerk T, Steel D: Use of intravitreal bevacizumab in a patient with a von hippel-lindau-associated retinal haemangioblastoma of the optic nerve head: A case report. Journal of Medical Case Reports 2008;2:182.

10 Hrisomalos FN, Maturi RK, Pata V: Long-term use of intravitreal bevacizumab (avastin) for the treatment of von hippel-lindau associated retinal hemangioblastomas. Open Ophthalmol J 2010;4:66-69.

11 Steeghs N, Rabelink TJ, op 't Roodt J, Batman E, Cluitmans FHM, Weijl NI, de Koning E, Gelderblom H: Reversibility of capillary density after discontinuation of bevacizumab treatment. Annals of Oncology 2010;21:1100-1105.

12 Keunen O, Johansson M, Oudin As, Sanzey M, Rahim SAA, Fack F, Thorsen F, Taxt T, Bartos M, Jirik R, Miletic H, Wang J, Stieber D, Stuhr L, Moen I, Rygh CB, Bjerkvig R, Niclou SP: Anti-vegf treatment reduces blood supply and increases tumor cell invasion in glioblastoma. Proceedings of the National Academy of Sciences 2011;108:3749-3754. 


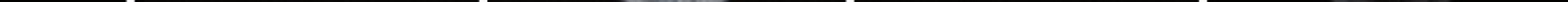

$\mathbf{A}$

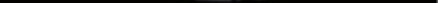

B
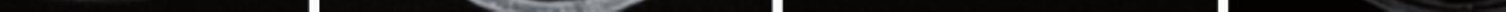
